\title{
GENDER WISE COMPARISON OF DISORDERED EATING ATTI- TUDES IN PHYSICAL EDUCATION PROFESSIONALS OF INDIA: A CROSS-SECTIONAL STUDY
}

\author{
Jupender Singh Bhagi ${ }^{1 \bowtie(0)}$, Dr. Kuljeet $\operatorname{Kaur}^{2}$ (1) and Dr. Sarita Tyagi ${ }^{3}$ \\ ${ }^{1}$ Research Scholar, Department of Physical Education and Sports Sciences, University of Delhi, India \\ ${ }^{2}$ Associate Professor, Physical Education, SRCC (University of Delhi), India \\ ${ }^{3}$ Associate Professor, Indira Gandhi Institute of Physical Education, University of Delhi, India
}
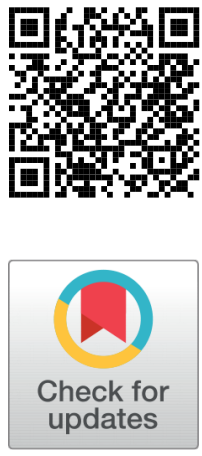

Received 31 May 2021

Accepted 14 June 2021

Published 30 June 2021

Corresponding Author

Jupender Singh Bhagi, jbhagi2612

@gmail.com

DOI $10.29121 /$

granthaalayah.v9.i6.2021.4003

Funding: This research received no specific grant from any funding agency in the public, commercial, or not-for-profit sectors.

Copyright: (C) 2021 The Author(s). This is an open access article distributed under the terms of the Creative Commons Attribution License, which permits unrestricted use, distribution, and reproduction in any medium, provided the original author and source are credited.

\section{ABSTRACT}

Motivation/Background: Eating disorders (ED) are serious psychological disorders characterized by unhealthy eating habits. There are a limited number of studies on eating disorders among male and female physical education professionals like teachers, coaches, and trainers. Therefore, the objective of this study was to examine the prevalence of disordered eating attitudes (EA) among the ones that are more or less associated with fitness, training and counseling the students and public in general.

Method: A survey study on 83 such professionals with at least 5 years of experience was being conducted through online questionnaire. The Eating Attitudes Test (EAT-26) was used.

Results: Of the 83 participants, $20 \%$ scored $\geq 20$ on the EAT- 26 . A significant positive correlation $(\mathrm{p}<.01)$ was found between age and body mass index (BMI) on EAT-26 scores.

Conclusions: Awareness regarding appropriate nutrition in relation to body weight is needed among professionals themselves before they counsel others to begin with and must therefore be cautious about their own eating patterns in the first place.

Keywords: Physical Education Professionals, North India, Eating Disorder, EAT26

\section{INTRODUCTION}

Unlike adults, the adolescents deal with their anxiety about their looks because of external pressures. Researching the root causes and identifying high-risk populations are necessary for effective treatment of eating disorders prevention and intervention in all age and gender categories. An increase in attention has been drawn to eating disorders recently because of their unique characteristics, bad outcomes, 
and mortality. The healthcare professionals, planners, epidemiologists, and patients all want to know about cases of anorexia and bulimia before counseling and provide interventions to cure the syndromes. Perry ((2019, March)); Talwar (2011)

According to "American Psychatric Association" (2017) , majority of people who have eating disorders exhibit disturbed behavior and emotions when they're under stress, not because they have a poor self-image of their own, which could stem from various sources such as low self-esteem, anorexia, or self-punishment. Those who suffer from eating disorders typically become obsessed with food and their weight. Though anorexia nervosa and bulimia mostly impact young women between the ages of 12 and 35, both gender older populations are equally vulnerable due to drastic social changes. In individuals with anorexia and bulimia, self-esteem is compromised, and the self is despised. Even when facing life-threatening semi-starvation, they typically "feel fat" and perceive themselves to be overweight (or malnutrition). An intense fear of gaining weight and becoming fat can lead to full-fledged paranoia. Proper diagnosis and the importance of timely intervention can be gauzed by the fact that a person who has an eating disorder is more likely to have other mental health issues, such as an anxiety disorder, a panic disorder, and drug abuse. Heredity may be a factor in why some people get disordered, but anorexia and bulimia are not limited to previous family members of anorexics and people. Severe emotional and physical symptoms can occur if the nutrition and overall health are neglected. Those who suffer from eating disorders can get proper medical attention and normalcy sooner than later.

According to "Psychology Today" (2019), the researchers, in industrialized countries estimate that about $2 \%$ of all women and about $0.8 \%$ of all men in those countries suffer from eating disorders. As per the Indian scriptures like Yog Sutra's, Vedant, Upanishads healthy eating (saattvik aaahar) is an absolutely essential part of the bodily routine, and the body has a built-in system to keep tabs on food intake. The manner in which we consume food can strongly influence our mod and behavior. Eating disorders have many root causes, disparate origins. An eating disorder may develop as a result of other anxiety about weight or body image concerns someone who begins to binge on food may not have enough self-control to stay thin or may eventually have an out-of-of-control eating disorder.

Despite the wide range of biological, behavioral, and social explanations for eating disorders, they remain challenging to study. A study by Perry ((2019, March)), showed that ten out of 100,000 people suffered anorexic nervosa in Indian men and 37.2 out of 100,000 Indian women, one of the most recognized eating disorders where an individual is normally dangerous.

\section{MATERIALS AND METHODS}

Objective: The primary objectives was to determine the eating attitudes concerns among physical education professionals and to determine any gender differences on 
eating attitudes.

Sample: 83 Physical education professionals working on full time basis spanning entire north India in the age group of 17 to 59 years of age.

Design: Survey; Cross-sectional study.

Instruments: Eating Attitudes Test (EAT-26): The EAT is most widely used screening questionnaire for abnormal eating attitudes. EAT has been widely translated and adapted in different languages, cultures, and countries. The EAT-26 used in the current study was originally developed by Garner et al. (1982) to evaluate attitudes, feelings, and preoccupations in relation to food, weight, and exercise. It has three subscales viz., dieting, bulimia and food preoccupation, and oral control.

\section{RESULTS AND DISCUSSIONS}

\begin{tabular}{|ccc|}
\hline Table 1 Reliability Statistics of the EAT-26 Scale \\
\hline Cronbach's Alpha & Cronbach's Alpha Based on Standardized Items & Number of Items \\
\hline 0.577 & 0.593 & 26 \\
\hline
\end{tabular}

A reliability analysis was carried out on the eating attitude test values scale comprising 26 items. Cronbach's alpha showed the questionnaire to reach fairly acceptable reliability, $\alpha=0.58$. Most items appeared to be worthy of retention, resulting in a decrease in the alpha if deleted. The one exception to this was item 11, which would increase the alpha to $\alpha=0.60$. As such, removal of this item can be considered. But owing to not much significant effect overall, it was decided to retain the said item.

Table 2 Descriptive Statistics and gender differences on demographic variables of the respondents

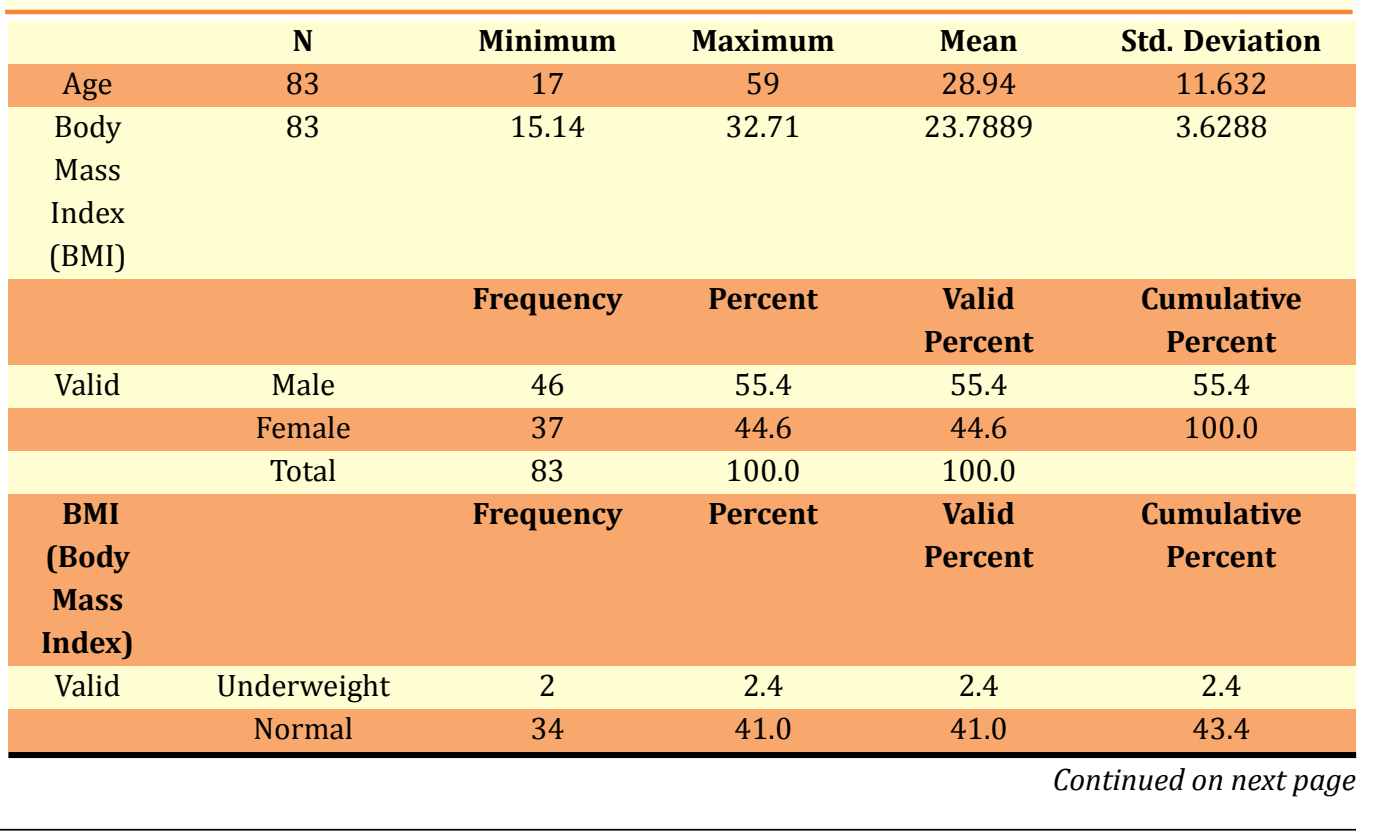




\begin{tabular}{ccccc}
\hline Table 2 continued & \multicolumn{3}{c}{} \\
\hline Overweight & 46 & 55.4 & 55.4 & 98.8 \\
Obese & 1 & 1.2 & 1.2 & 100.0 \\
Total & 83 & 100.0 & 100.0 & \\
\hline
\end{tabular}

Table 2 shows that a total of 83 physical education professionals from North India comprised the sample for the study. The mean age was $28.94+11.63(17-59)$ years. $20 \%$ (17 out of 83 ) of the respondents scored more than 20 on EAT-26 scale showing that they required referral for eating disorder. In terms of gender distribution, 46 were males and 37 were females. Mean body mass index (BMI) for the sample was $23.78+3.62$. Out of the total of 83 respondents, 2 were underweight $(\mathrm{BMI}<18), 34$ were normal BMI (BMI between18 to 23.5), 46 were overweight (BMI between 23.6 to 30$)$ and 1 was obese (BMI>=31. In order to evaluate objective of gender differences on eating attitude, the whole sample was divided into two groups on the basis of gender, i.e., Group A (males; $n=46$ ) and Group B (females; $n=37$ ). On comparing both (gender) groups across the psychological variable (EAT-26), males had nonsignificantly higher scores on dieting subscale of EAT-26 (Total score). Both groups were comparable on other subscales and parameters.

Table 3 Gender wise and body mass index wise scores of respondents on EAT-26 scale with minimum and maximum EAT-26 scores

\begin{tabular}{|c|c|c|c|c|c|c|c|}
\hline Gender & & Mean & $\mathbf{N}$ & $\begin{array}{c}\text { Std. } \\
\text { Deviation }\end{array}$ & $\begin{array}{c}\text { \% of Total } \\
\mathbf{N}\end{array}$ & $\begin{array}{l}\text { Mini- } \\
\text { mum }\end{array}$ & $\begin{array}{l}\text { Maxi- } \\
\text { mum }\end{array}$ \\
\hline \multirow[t]{4}{*}{ Male } & normal & 10.79 & 19 & 5.97 & $22.9 \%$ & 1 & 21 \\
\hline & overweight & 14.54 & 26 & 6.76 & $31.3 \%$ & 3 & 28 \\
\hline & obese & 8.00 & 1 & & $1.2 \%$ & 8 & 8 \\
\hline & Total & 12.85 & 46 & 6.60 & $55.4 \%$ & 1 & 28 \\
\hline \multirow[t]{4}{*}{ Female } & $\begin{array}{l}\text { under- } \\
\text { weight }\end{array}$ & 17.50 & 2 & 4.95 & $2.4 \%$ & 14 & 21 \\
\hline & normal & 11.27 & 15 & 6.05 & $18.1 \%$ & 2 & 23 \\
\hline & overweight & 13.40 & 20 & 7.35 & $24.1 \%$ & 4 & 31 \\
\hline & Total & 12.76 & 37 & 6.77 & $44.6 \%$ & 2 & 31 \\
\hline \multirow[t]{5}{*}{ Total } & $\begin{array}{l}\text { under- } \\
\text { weight }\end{array}$ & 17.50 & 2 & 4.95 & $2.4 \%$ & 14 & 21 \\
\hline & normal & 11.00 & 34 & 5.92 & $41.0 \%$ & 1 & 23 \\
\hline & overweight & 14.04 & 46 & 6.97 & $55.4 \%$ & 3 & 31 \\
\hline & obese & 8.00 & 1 & & $1.2 \%$ & 8 & 8 \\
\hline & Total & 12.81 & 83 & 6.64 & $100.0 \%$ & 1 & 31 \\
\hline
\end{tabular}

Figure 1 shows the more presentable line plot of eating attitude scores of males and females being classified as normal, underweight, over weight and obese as per their body mass indexes. The scores above 20 on EAT- 26 scale has been marked as a constant at 20; a straight line. As per the test instructions, any score above 20 means that the person concerned requires a referral owing to eating disorder.

On comparing the psychosocial variables alongside the EAT-26 scores (Table 4 ), it was seen that, apart from the dieting subscale, both genders were comparable 


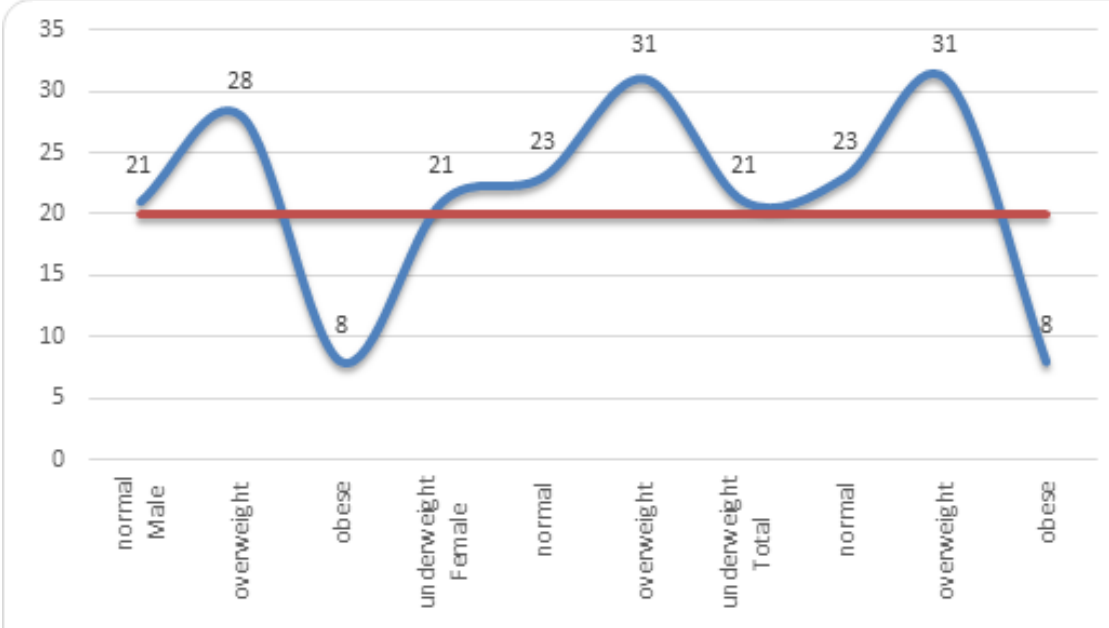

Figure 1 Line chart showing EAT-26 score values over and under the standard EAT-26 score value of 20

Table 4 Independent t-test showing gender differences on Eating attitude

\begin{tabular}{ccccccc}
\hline Gender & & N & Mean & $\begin{array}{l}\text { Std. Devi- } \\
\text { ation }\end{array}$ & $\begin{array}{l}\text { Std. Error } \\
\text { Mean }\end{array}$ & t-test \\
Total EAT-26 Score & Male & 46 & 12.85 & 6.606 & 0.974 & 0.062 \\
& Female & 37 & 12.76 & 6.776 & 1.114 & \\
\hline Dieting & Male & 46 & 6.83 & 4.160 & 0.613 & -0.31 \\
\hline $\begin{array}{c}\text { Bulimia and food pre } \\
\text { occupation }\end{array}$ & Female & 37 & 7.14 & 4.917 & 0.808 & \\
\hline & Male & 46 & 1.41 & 1.869 & 0.276 & 0.903 \\
Oral control & Female & 37 & 1.24 & 2.127 & 0.350 & \\
\hline & Male & 46 & 3.93 & 2.284 & 0.337 & $0.022^{*}$ \\
\hline
\end{tabular}

*significant at .05 level

on other subscales and total score of EAT-26. Non-significant score differences on "dieting" and "Bulimia" for males and females could be reflective of the similarity on expected tendency of both males and females to be equally focused on dieting and avoidance of fatty food, in the Indian culture. It is interesting to note that the mean oral control sub-scale variable score indicating was significantly higher for the males in comparison to female indicative of higher tendency of eating related psychological distress in males than females. Although Srinivasan et al. (2000) had studied gender differences in students from medical field, but we are unable to make any direct comparison with their findings as they used the Bulimia Investigatory Test rather than EAT-26 test. There was a dearth of studies from India that assessed gender differ- 
ences and body shape concerns in physical education professionals. In view of rapid socio-cultural changes that are impacting attitudes, habits, and lifestyle, behaviors, and psychopathology relating to eating and body shape needs to be studied in a comprehensive and holistic manner before designing any interventions.

\section{CONCLUSIONS AND RECOMMENDATIONS}

In a special subpopulation of physical education professions without any comorbidity from North India based on gender, similarities outweighed differences on EAT-26 when compared for eating attitudes. The significant difference that emerged on oral control (EAT-26) was not robust and it was inconsistent. Additionally, a strong positive relationship between age and body mass index is an obvious outcome. Future studies need to focus on trying to understand the cultural variations also in eating attitudes, body shape concerns, and eating disorders in the Indian subcontinent using a longitudinal design, using culturally appropriate instruments too for better understanding and more meaningful analysis of the results.

\section{ACKNOWLEDGEMENTS}

People who contributed to the work but do not fit criteria for authorship should be listed in the Acknowledgments, along with their contributions. It is advised that authors ensure that anyone named in the acknowledgments agrees to being so named. Funding sources that have supported the work should also be cited.

\section{REFERENCES}

American Psychatric Association. (2017). Retrieved from Https://Www.Psychiatry .Org/Patients-Families/Eating-Disorders/What-Are-Eating-Disorders

RetrievedFromWww

Garner, D. M., Olmsted, M. P., Bohr, Y., \& Garfinkel, P. E. (1982). The Eating Attitudes Test: psychometric features and clinical correlates. Psychological Medicine, 12(4), 871878. Retrieved from https://dx.doi.org/10.1017/s0033291700049163 10.1017/ s0033291700049163

Perry, N. ((2019, March)). Retrieved from Https://Www.Healthissuesindia.Com/2019/ 03/09/Eating-Disorders-Are-All-But-Unstudied-In-India/.RetrievedFromWww .Healthissuesindia.Com:Www.Healthissuesindia.Com

Psychology Today. (2019). Retrieved from Https://Www.Psychologytoday.Com/Us/ Conditions/Eating-Disorders.RetrievedFromWww.Psychologytoday.Com:Https:// Www.Psychologytoday.Com/Us/Conditions/Eating-Disorders

Sharan, P., Gupta, N., Bhargava, R., \& Chavan, B. (2017). Eating attitudes and body shape concerns among medical students in Chandigarh. Indian Journal of Social Psychiatry, 33(3), 219-219. Retrieved from https://dx.doi.org/10.4103/0971-9962.214605 10.4103/ 0971-9962.214605

Srinivasan, T. N., Suresh, T. R., \& Jayaram, V. (2000). Emergence Of Eating Disorders In India: Study Of Eating Distress Syndrome And Development Of A Screening Questionnaire. 
Indian J Soc Psychiatry, 16, 81-90.

Talwar, D. P. (2011). Factorial Analysis Of The Eating Attitude Test (EAT-40) Among A Group Of Malaysian University Students. 